\title{
SPATIAL-DYNAMIC CHANGES OF FORESTS STRUCTURES IN THE GREEN ZONE OF IRKUTSK CITY FOR LAST DECADES (South -West Pre-Baikal)
}

\author{
Alexander Sizykh*, Ruslan Moritz \\ Siberian Institute of Plant Physiology and Biochemistry SB RAS, 664033, Irkutsk, Lermontova str., 132, Russia \\ "Corresponding author Alexander Sizykh, e-mail: alexander.sizykh@gmail.com;
}

Received December 2018; Accepted Jaunary 2019; Published February 2019;

DOI: https://doi.org/10.31407/ijees9125

UOI license: http://u-o-i.org/1.01/ijees/91819684

\begin{abstract}
Main properties, which a city green zone must include are environment protection, environment formation, as well as sanitary-hygienic and recreational functions. Due to this fact, provision of such studies with information is one of the most complicated aspects while analyzing the materials obtained and available archival data. There are nowadays several hundreds applied-research methods for analytical examination of geoecological problems including data characterizing biota on the territories surrounding large population aggregates, such as cities, settlements, etc. An important fact is a territorial location of a population aggregate with its physical-geographic conditions, as well as with history of general formation and development of this or that population aggregate. Large population aggregates (cities, settlements) of the East Siberia are located under different natural and climatic conditions, in different natural zones and territories. In this paper, problems of spatial-temporal changes in the structure of forests surrounding Irkutsk City are reported. Irkutsk City is situated in the south of the East Siberia (in Pre-Baikal).
\end{abstract}

Key words: spatial-dynamics changes of forests, green zone, south-west Pre-Baikal 